\title{
PROPUESTA DE EDUCACIÓN MORAL DESDE UNA PERSPECTIVA FILOSÓFICA PARA LA ESCUELA PRIMARIA
}

Diego Antonio Pineda R.

Pontificia Universidad Javeriana

[...] es fácil observar que los conceptos éticos pueden ser bien comprendidos, en consonancia con su edad, por el niño, por el muchacho y por el joven; y que toda nuestra vida no es otra cosa que aprender a comprender, de una forma cada vez más profunda, su significado y su extensión, en verlos reflejados mediante ejemplos continuamente renovados y sólo así conocer, de una forma cada vez más detallada, la gran amplitud de su sentido, el carácter determinado de su aplicación. De hecho, si se quisiera esperar, para familiarizar al hombre con esta temática, hasta que él fuera completamente capaz de percibir los conceptos éticos en toda su verdad, pocos llegarían a poseer esta capacidad, y estos pocos apenas lo lograrían antes del final de su vida. Sería la falta misma de reflexión ética la que retrasaría la formación de esta capacidad perceptiva así como la del sentimiento ético. Ocurre con esto lo mismo que con otras representaciones y conceptos, cuya comprensión comienza asimismo por un conocimiento no comprendido, y sería lo mismo que si se exigiese que sólo un general hubiese de conocer la palabra batalla, dado que sólo él sabe verdaderamente lo que es una tal.

Pero no se trata meramente de comprender, sino que los conceptos morales y su expresión deben alcanzar también solidez en la representación del ánimo; mas, a tal efecto, deben ser inculcados tempranamente; ellos contienen las características básicas y el fundamento de un mundo interior, más elevado, y, consolidados en la juventud, constituyen un tesoro, que tiene vida en él mismo, que continúa echando raíces en sí y creciendo, que se enriquece mediante la experiencia y que también se confirma cada vez más respecto a la inteligencia y a la convicción.

G. W. F. Hegel

La ética es la rama de la filosofía que intenta comprender la conducta moral. Ella representa una investigación objetiva y desapasionada sobre problemas y situaciones morales. Su fin nunca puede ser el adoctrinamiento, sino, más bien, el de ayudarle a los individuos a que comprendan más claramente sus posibilidades morales en situaciones dadas.

[...] Los niños y jóvenes deben aprender a identificar los problemas morales, y a pensar sobre ellos, pues tal reflexión es lo que constituye la investigación ética en su sentido más propio. El objetivo de la investigación ética no es el de enseñar a los niños y jóvenes un cierto 
conjunto de valores particulares, sino, más bien, el de permitirles una consideración constante, nunca terminada y permanentemente abierta de los valores, criterios y prácticas de acuerdo con los cuales vivimos, para que ellos los discutan de forma abierta y pública tomando en cuenta todos los hechos y los puntos de vista que están en juego. Es un postulado básico de la investigación ética que tal discusión y reflexión debe tener lugar en una atmósfera de confianza y respeto mutuo, así como de imparcialidad, puesto que ello contribuye a fomentar la responsabilidad e inteligencia morales de los niños y jóvenes mucho más que cualquier otro sistema que se limite a familiarizarlos con "las reglas" y que insista en que ellos "cumplan con su deber".

Matthew Lipman

\title{
Resumen
}

En sentido estricto, la ética no puede ser enseñada, pero de modo indirecto, a través de la narración literaria, por medio de cuentos, se puede incentivar el aprendizaje, de tal manera que se promueva a través de los relatos las excelencias o virtudes. La reflexión sobre la ética puede ser aprendida en la medida en que se cultiven hábitos de deliberación sobre los comportamientos lo cual requiere una mediación filosófica. Por esta razón, la ética no se pude aprender de la misma manera que la biología o la física, pues requiere del examen de los conceptos éticos en situaciones específicas. Los niños no tienen la posibilidad de aprender con exposiciones simplemente abstractas o generales desvinculadas de toda realidad. Como caso ejemplar dela didáctica exponemos el aprendizaje de la virtud de la valentía.

Palabras clave: didáctica de la filosofía. Enseñanza de la filosofía.

\begin{abstract}
Primary School Moral Education Proposal from a philosophical perspective.

In a strict sense, ethics cannot be taught. However, in an indirect way, through literary narration and tales, it is possible to encourage this learning by promoting virtues through stories. The reflection on ethics can be learned if habits of deliberation on behaviors are cultivated, which require philosophical mediation. For this reason, ethics cannot be learned in the same way as biology or physics because it requires the evaluation of ethical concepts in specific situations. Children do not have the opportunity to learn with abstract and generalized reports, that are unrelated to reality. As an exemplary case of didactics we present the learning of the virtue of courage.
\end{abstract}

Key Words: Didactics for philosophy. Teaching philosophy

\section{INTRODUCCIÓN}

La ética tiende a considerarse, cada vez más, como un elemento esencial en la formación de cualquier persona, tanto en la educación básica como en la propia formación profesional. En Colombia, la Ley General de Educación, Ley 115 de 1994, la declara un área obligatoria y fundamental (Art. 23) y le exige a los directivos de los planteles educativos que promuevan la 
formación ética en todas las áreas del currículo y en todos los ámbitos de la comunidad educativa (Art. 25). Exige, así mismo, la formación de educadores "de la más alta calidad científica y ética" (Art.109).

Por esta y otras razones, surgen a diario propuestas diversas sobre cómo desarrollar, en la escuela primaria y secundaria, e incluso en la formación superior, esta dimensión esencial en la formación de una persona. Infortunadamente, los diversos intentos por formar el criterio ético de los niños y jóvenes terminan, casi siempre, por promover prácticas indeseables, como el adoctrinamiento moral, el subjetivismo o el más vulgar relativismo, que, antes que desarrollar un carácter moral, terminan por confundir seriamente el sentido moral de los individuos.

La necesidad de formar la capacidad de juicio moral de los alumnos parece, a todas luces, autoevidente, no solo por tratarse de una dimensión esencial de la persona, sino, también, porque las complejas condiciones del mundo contemporáneo (con su elevado desarrollo tecnológico y las exigencias de un mundo abierto y pluralista) plantean hoy a los individuos nuevos retos éticos. La forma como esto deba hacerse, sin embargo, es cada vez más problemática. ¿Acaso es posible que una adecuada educación moral pueda hacerse por vía directa, es decir, por medio de la enseñanza de un determinado conjunto de conocimientos, habilidades y actitudes que los niños y jóvenes "deben aprender"?

La pregunta clásica de los antiguos filósofos griegos sobre si es posible enseñar la virtud sigue hoy tan vigente como hace veinticinco siglos. No pretendo dar aquí una respuesta definitiva a tan interesante pregunta ${ }^{1}$, aunque, sin duda, habré de abordarla, sino ofrecer algunas reflexiones personales, acompañadas de algunas propuestas que he venido elaborando en los últimos años en torno a la posibilidad y sentido de la reflexión ética con los niños, y también en torno a algunas estrategias que pueden ser utilizadas en la educación moral en la escuela primaria.

No pretendo, en este sentido, decir cómo se debe "enseñar la ética", pues precisamente creo que, aunque es posible formar la capacidad de juicio ético de los niños y jóvenes a través del examen de situaciones vitales con base en herramientas de análisis y reflexión que nos proporciona el ejercicio de la reflexión filosófica, no es posible "enseñar ética" de una forma semejante a como se enseñan, por ejemplo, las ciencias naturales.

Que algo no pueda ser enseñado no quiere decir, sin embargo, que no pueda o no deba ser aprendido. Creo precisamente que la reflexión ética es algo que puede ser aprendido en la medida en que uno adquiera y cultive los hábitos reflexivos que implica un comportamiento ético; y, sobre todo, que tal aprendizaje sólo es posible por la mediación de una educación filosófica. Lo que voy a presentar debe entenderse también, entonces, como una crítica severa y radical del modo como ordinariamente se pretende "enseñar ética", como si esto fuera algo semejante a la enseñanza de disciplinas como las matemáticas, la biología o la geografía; y,

\footnotetext{
${ }^{1}$ El más interesante examen de la clásica pregunta de los griegos en la filosofía contemporánea es el que hace el filósofo inglés Gilbert Ryle en su artículo citado en la bibliografía que se encuentra al final de este texto. También es útil para comprender la problemática de la formación de las virtudes morales en la antigüedad el texto de Marco Zingano, cuya referencia completa también se encuentra al final de este escrito.
} 
sobre todo, cuando a través de tal enseñanza se pretende "inculcar"2 en los individuos un cierto conjunto de valores preestablecidos o simplemente dar lugar a una fácil "opinadera" en cuestiones morales, que sólo promueve un vulgar relativismo.

Para abordar mejor el problema que aquí quiero plantear, debo empezar por examinar dos cuestiones fundamentales. En primer término, habré de retomar, de forma general, el interrogante clásico en torno a la posibilidad de la enseñanza de la virtud moral; en segundo término, intentaré mostrar por qué y cómo es posible concebir al niño como un sujeto de reflexión ética, y no sólo como un objeto de educación moral, como hasta ahora se ha hecho. Sobre la base de estas dos clarificaciones previas, intentaré mostrar en qué habrá de consistir una educación moral concebida desde una perspectiva filosófica, para, finalmente, ofrecer algunos ejemplos específicos de en qué podría consistir dicha educación moral de carácter filosófico. Para esto último me valdré de algunos ejemplos tomados de mi libro El miedo es para los valientes y otros cuentos para la reflexión ética.

\section{Una mirada a la pregunta clásica por la enseñanza de la virtud moral}

Las sociedades democráticas contemporáneas se basan en un supuesto fundamental: que están constituidas por ciudadanos, y no por esclavos, súbditos o vasallos. El ciudadano no está determinado por el mismo tipo de relaciones sociales que determinaban al vasallo de la época feudal, que se comprometía, bajo juramento, a obedecer en todo a su señor, quien, a cambio, le ofrecía protección para su vida. Se diferencia del mero súbdito, propio de las monarquías absolutas, que no solo se encontraba bajo la autoridad absoluta de un monarca, sino que incluso debía estar dispuesto a dar la vida por él. Es muy diferente también del esclavo (antiguo o moderno), que vive bajo un régimen de explotación y dominación económica, política y cultural que le impide desarrollarse como persona.

El ciudadano es un sujeto de derechos y deberes que, cuando obra, intenta hacerlo de forma autónoma, es decir, basado en convicciones que son razonables y que pueden ser defendidas públicamente mediante una buena argumentación; es, por tanto, un individuo en capacidad de participar efectivamente en las decisiones que le afectan y de construir su propia identidad dentro del marco de diferencias de distinto orden (de género, raza, religión, costumbres, etc.), $\mathrm{y}$, sobre todo, es un sujeto reflexivo que, a la vez que cuida de sus intereses, participa intelectual, emocional y prácticamente en la construcción de una sociedad pluralista y cada vez más justa.

Lo que garantiza la existencia de una sociedad democrática no son solo las leyes, o incluso ciertas instituciones (como el Parlamento, el sistema electoral o un sistema de administración de justicia independiente del Ejecutivo y del Legislativo), ni siquiera que se reconozcan formalmente ciertos derechos a los individuos o existan mecanismos de participación; lo esencial para que una democracia funcione efectivamente es la existencia de ciudadanos

\footnotetext{
2 El verbo "inculcar", hoy tan socorrido, tiene un sentido bastante sospechoso. Proviene del verbo latino "calcare", que quiere decir algo así como "introducir algo forzadamente, a presión". De allí proviene, por ejemplo, el término "calzado": el calzado es aquello que entra ajustadamente, a presión. El prefijo "in" (de inculcare) refuerza este sentido de introducir algo a presión, empujándolo, "a patadas". "Inculcar" es, pues, introducir o meter algo a la fuerza, por medio de una presión externa. ¿Qué dirían al respecto los que hoy tanto insisten en la necesidad de "inculcar" valores o conocimientos?
} 
capaces de hacer valer sus derechos y de cumplir responsablemente con sus deberes, de ser tolerantes con las diferencias, de las que además buscan enriquecerse, y, sobre todo, ciudadanos que tienen la capacidad de pensar por sí mismos, de hacer juicios propios, y que están dispuestos a participar activamente en las decisiones sociales.

Es precisamente dentro de este ámbito de la ciudadanía democrática que tiene sentido plantear la necesidad de la formación ética de los ciudadanos. El fin de la educación moral no puede ser, desde esta perspectiva, simplemente el de hacernos "personas mejores" o más buenas, si por ello se entiende simplemente cumplir con ciertos deberes y obligaciones o "no hacer daño a los demás". La formación ética en una sociedad democrática tiene un sentido claramente político, pues lo que está en juego allí es la formación de ciudadanos capaces de participar activamente en la construcción de la vida pública, ciudadanos capaces de resolver de forma sensata y razonable sus diferencias, ciudadanos que se reconocen mutuamente en sus diferencias.

Subsiste, sin embargo, una pregunta fundamental: ¿cómo se puede formar para ello? ¿No es acaso algo que convendría, más bien, dejar a la espontaneidad, o al simple arbitrio de cada persona? ¿O será necesario, más bien, establecer programas y cursos de ética a todos los niveles de nuestro sistema educativo, al igual que hay cátedras de matemáticas, historia o lenguaje? Una pregunta semejante a esta fue la que enfrentó a Sócrates con los sofistas en la antigua Grecia. Según nos cuenta Platón en muchos de sus diálogos, Sócrates preguntaba a Protágoras y a otros sofistas si era posible enseñar la virtud. Detrás de este asunto se plantea no simplemente el hecho de si pueden ser enseñadas cosas como la justicia, la bondad o la valentía, sino sobre todo la posibilidad de que podamos pensar en un plan de formación para el pleno ejercicio de la ciudadanía. La areté (palabra que ordinariamente se traduce por "virtud", "excelencia" o "perfección"), tal como la concibieron los filósofos de la antigüedad, es precisamente aquello que nos hace posible ser buenos ciudadanos. Pero, ¿debe esto aprenderlo cada uno por su cuenta? ¿O es, más bien, el simple resultado de la adquisición de una serie de hábitos, adquisición que solo es posible en el marco de una sociedad centrada en la participación activa de los ciudadanos? ¿O es posible acaso que haya maestros especialmente encargados de esta tarea, e incluso un programa específico para ello?

Para responder positivamente a esta posibilidad de enseñar la virtud, nos encontramos, de entrada, con una primera dificultad: es claro que algunas de las virtudes básicas que hacen posible la vida ciudadana (la justicia, la moderación, la prudencia, la valentía, la amabilidad, etc.) no pueden enseñarse del mismo modo que se enseñan la geografía o la biología. Puesto que no hay ni una cátedra ni un currículo ni un maestro especializado para la enseñanza de la justicia, la bondad o la paciencia, parecería, entonces, que es del todo imposible tal enseñanza.

Hay, sin embargo, muchas cosas que se pueden aprender sin la mediación de una enseñanza formal y directa. Tal ocurre, por ejemplo, con el aprendizaje de la lengua materna. No se requiere para ello ni de una cátedra, ni de un currículo, ni de un maestro especializado. Y, sin embargo, todos aprendemos a hablar nuestra lengua materna de forma más o menos eficiente. ¿Algo semejante podría ocurrir, tal vez, cuando se trata de formarnos como ciudadanos competentes? Tal es lo que sugiere Protágoras en su diálogo con Sócrates. Según él, las virtudes que se requieren para el buen ejercicio de la ciudadanía se empezarían ya a aprender desde niños, en el hogar, el barrio o el círculo de amigos; no requerirían, por ello de un investigador especializado, pues se trataría de asuntos respecto de los cuales todos tenemos 
algún conocimiento. Sólo, según él, en algunos casos especiales, en los que podría haber particulares sutilezas o complejidades, requeriríamos de un experto, al igual que acudimos a un texto de gramática, un diccionario o un especialista en fonética cuando nos tropezamos con sutilezas de nuestra lengua que desbordan nuestra comprensión intuitiva.

La analogía que hace Protágoras entre el aprendizaje de la lengua materna y el de las virtudes ciudadanas tiene, sin embargo, sus límites, pues, por una parte, las virtudes morales que requiere el ejercicio de la ciudadanía ni son innatas ni se adquieren de forma espontánea por el simple hecho de vivir en la ciudad o tomar contacto con otros ciudadanos. Tampoco son, sin embargo, meras habilidades o destrezas que se pueden alcanzar tras un paciente entrenamiento o una constante supervisión. La educación ciudadana, desde luego, tiene que ver también con el desarrollo de virtudes morales como la justicia, la prudencia o la valentía. Y, sin embargo, tales cosas parece que no pueden ser enseñadas de forma directa. Sólo se pueden aprender de forma práctica en el ejercicio mismo de la convivencia con otros en el hogar, la escuela, el grupo de amigos o la comunidad local. No hay, pues, una respuesta fácil al interrogante socrático, pues las condiciones que se requieren para el ejercicio de la ciudadanía son de diferente orden, y no todas parecen enseñables.

Así pues, y si bien las virtudes propias de la vida ciudadana no son enseñables de forma directa, o por lo menos no son enseñables del mismo modo que lo son las disciplinas científicas, nada niega la posibilidad de que el ciudadano pueda aprender las virtudes morales, si aceptamos el supuesto de que no todo aprendizaje requiere de la mediación de la enseñanza. Hay, de hecho, muchas formas de aprendizaje que no son precisamente el resultado de la enseñanza directa, sino del propio esfuerzo del individuo por desarrollar una perspectiva propia sobre las cosas. Nadie tendrá que enseñarme qué es lo justo (si es que fuese posible que alguien enseñara tal cosa) para que yo me vaya formando una cierta noción de lo que es justo y para que haga permanentemente juicios sobre la justicia de ciertas acciones, valoraciones o decisiones.

Creo, con Aristóteles ${ }^{3}$, que las virtudes morales, como las artes, sólo se aprenden a través del ejercicio, de la práctica metódica y continuada, y no de la mediación de una enseñanza formal. No hay ni debe haber "maestros de moral", en el sentido de personas que hayan de indicarnos cuál es el camino recto que debemos seguir, sino compañeros de indagación que, puesto que viven problemas semejantes a los nuestros, han incurrido en errores como los nuestros y tienen aspiraciones vitales como las nuestras, pueden ayudarnos a aclarar en un momento determinado cuál es el camino que debemos elegir.

Un buen maestro en cuestiones morales no tendría en principio que enseñarnos nada (al menos nada de forma directa, como lo hace el profesor de ciencias naturales o el de lenguas extranjeras). Debería, más bien, ayudarnos a identificar y a examinar mejor nuestras propias

\footnotetext{
${ }^{3}$ Dice Aristóteles al comienzo del Libro II de la Ética nicomaquea (1103a 33-1103 b 13) lo siguiente: “[...] todo lo que hemos de hacer después de haberlo aprendido lo aprendemos haciéndolo, como, por ejemplo, llegamos a ser arquitectos construyendo y citaristas tañendo la cítara. [...] de las mismas causas y por los mismos medios nace y se estraga toda virtud, como también todo arte. Del tañer la cítara resultan los buenos y los malos citaristas, y análogamente los arquitectos y todos los demás artífices. Construyendo bien serán buenos arquitectos, y construyendo mal, malos. Si así no fuese, para nada se necesitaría del maestro, ya que todos serían nativamente buenos o malos artífices".
} 
opciones morales, planteándonos preguntas, obligándonos a revisar nuestros argumentos y nuestros usos del lenguaje, cuestionando nuestros supuestos, ayudándonos a prever las posibles consecuencias de nuestros actos. Un buen maestro, desde esta perspectiva, no es tanto el que nos enseña algo, sino el que nos sirve como una instancia de corrección de nuestro propio aprendizaje.

El aprendizaje moral, semejante en muchas cosas al aprendizaje de las artes, es un aprendizaje práctico que se da a través de la participación en una comunidad de vida en la que se adquieren determinados hábitos y prácticas y que sólo podrá perfeccionarse a través de la reflexión que los propios individuos hagan sobre sus propias prácticas. El gran problema con este tipo de aprendizaje se presenta, entonces, cuando las generaciones mayores pretenden que quienes se forman para ser buenos ciudadanos deben limitarse a reproducir las prácticas ya existentes, simplemente a cumplir deberes o reglas abstractas sin que haya posibilidad de que tales "deberes" y "reglas" puedan ser examinados y puestos en cuestión, o a aceptar como ya dados, como absolutos e indiscutibles, los supuestos "valores" que una generación anterior a la suya considera como fundamentales.

Lo que se debe esperar, entonces, de una persona moralmente educada no es que cumpla con todas sus obligaciones, que respete todas las reglas, que valore todo lo que los mayores ya valoramos, sino que haga el esfuerzo por comprender el significado de las reglas que hacen posible la convivencia, que defina por sí misma aquellas cosas que considera valiosas, que intente clarificarse por sí mismo y, en circunstancias concretas, qué tipo de cosas son las que debe representarse como deberes; en fin, que sus prácticas morales tengan un carácter autorreflexivo.

Una nueva dificultad, sin embargo, aparece en este punto. Si lo que esperamos de una persona moralmente educada, más que el seguimiento de reglas o el cumplimiento de deberes abstractos, es que actúe de forma sensata a partir de un trabajo autorreflexivo; y si, por otra parte, suponemos que esa persona moralmente reflexiva es y puede ser un niño, ¿no incurriremos con ello en una contradicción? Tal es el interrogante que tendremos que abordar a continuación.

\section{El niño como sujeto de reflexión ética}

¿Pueden los niños, aún los más pequeños, ser sujetos de reflexión ética?, es decir, ¿están en condiciones de reflexionar sobre su acción de una forma propia, a partir de la visión limitada que tienen del mundo, pero tomando, sin embargo, en cuenta los múltiples factores que determinan su acción? Tal es la pregunta básica que a continuación abordaré.

La pretensión que está en el fondo de la anterior pregunta parece, de entrada, completamente exagerada y, en cierto sentido, autocontradictoria. ¿Cómo se puede creer que los niños sean capaces de reflexionar sobre el sentido moral de sus acciones cuando es un hecho por todos aceptado que son dependientes de los adultos, tanto física como psicológica y, sobre todo, moralmente? ¿Cómo se puede pretender que tomen en cuenta los diversos factores que determinan su acción (motivos, circunstancias, consecuencias, razones, etc.) cuando ni siquiera tienen claro de qué se tratan tales cosas y cuando en sus acciones parecen ser más bien impulsivos y poco reflexivos? 
La concepción que tenemos habitualmente de lo que son la educación y la propia infancia parece excluir de entrada la posibilidad que señalamos. En efecto, a lo largo de toda nuestra historia, los niños, aunque han sido el objeto de la educación moral, difícilmente podrían ser reconocidos como sujetos de reflexión ética.

Cuando digo que los niños han sido por siglos el objeto de la educación moral, lo que quiero poner de presente es el hecho de que todo el discurso moralizante de la sociedad está dirigido a ellos en primer lugar. La literatura infantil ha pretendido por mucho tiempo, a través de las fábulas morales y de cuentos bien intencionados, enseñarles de forma directa qué es lo que deben hacer, cuál es su deber o qué reglas son las que deben cumplir. Infortunadamente, esas formas de dirigirse a los niños, por bien intencionadas que sean, fallan a la hora de dar en el blanco, pues, en vez de promover su capacidad de reflexionar sobre su acción, alimentan su heteronomía, es decir, sirven solo para enseñarles qué es lo que, según otros (los mayores, los adultos, las personas investidas de autoridad), ellos deberían hacer, lo que deberían valorar, la forma como deberían comportarse.

Los niños, por cierto, saben esto tan bien que aprenden fácilmente a dar a los adultos las respuestas que ellos esperan. Con esto, sin embargo, sólo eluden su consideración del problema, y, puesto que los mayores quedan satisfechos, ellos emprenden su propia búsqueda en nuevas direcciones. De esta forma, aunque una buena parte de la instrucción moral que les proveemos suelen asimilarla sin mayor capacidad de examen -y buena parte de ella, además, termina por pesar por muchos años sobre su conciencia-, la verdad es que, porque a ellos mismos les resulta necesario, se ven obligados a construir poco a poco sus propios criterios y principios morales.

Hay problemas éticos que preocupan particularmente a los niños, como el de las mentiras, el de la crueldad o el de la injusticia. Es claro, sin embargo, que esos problemas no aparecen en ellos formulados en primer lugar en términos abstractos. Ellos no se preguntan, por ejemplo, por qué está mal mentir o cuál es el origen de la injusticia existente en el mundo. Sin embargo, muy fácilmente captarán que hay una clara contradicción entre lo que verbalmente les dicen sus padres y maestros (por ejemplo, que no deben decir mentiras) y muchas de sus acciones efectivas (como, por ejemplo, cuando los adultos dicen, tras una llamada telefónica, y en presencia de los propios niños, "digan que no estoy"). Así mismo, son muy sensibles ante actos específicos de injusticia que se dan en su casa o en los salones de clase, como, por ejemplo, los privilegios injustificados que se dan a otro de sus hermanos o hermanas o el trato poco cordial, e incluso agresivo, que algunos de sus compañeros les dan a otros.

Es claro, entonces, que los niños se plantean, ya desde pequeños (por lo menos desde que adquieren un cierto dominio del lenguaje y entran de una forma más directa en el intercambio social con otros niños, con el círculo familiar más amplio y, especialmente, cuando entran de lleno en la experiencia socializadora por excelencia, la escuela), preguntas y problemas de orden moral. “¿Qué es lo que está mal en el hecho de decir mentiras -podría preguntarse un niño cualquiera- si, al fin y al cabo, todos parecen decir mentiras, incluso aquellos, como los propios padres y maestros, que nos enseñan que no debemos hacerlo?". "Si aceptamos que la crueldad es mala, pues de hecho parece producirnos una repugnancia inmediata -se podría 
preguntar otro-, ¿por qué, sin embargo, parece que hay personas que disfrutan de ciertos actos crueles, como aquellos en que se hace sufrir a ciertos animales sin justificación alguna?”. ¿Es cruel toda forma de injusticia? ¿Es injusta toda forma de crueldad? ¿Hay razones que justifiquen que a unos niños se otorguen derechos especiales, o privilegios, o debería, más bien, darse a todos y en todas las circunstancias los mismos derechos y obligaciones?

Sin pretender afirmar que los niños sean una especie de pequeños "filósofos morales" (como en alguna parte lo sugiere Lawrence Kohlberg), lo que quiero poner de presente es que los niños, porque la experiencia misma se los exige, se ven obligados más de una vez a plantearse problemas éticos. Los ejemplos que he puesto son, por supuesto, solo los más evidentes. Se podrían citar, por cierto, muchos otros casos en que incluso llegan más lejos, y hasta se preguntan por el valor de principios éticos fundamentales, como el caso de un pequeño niño que, al verse desplazado por sus otros amigos a la hora de ver su programa de televisión favorito, planteó a su mamá el siguiente interrogante: "Mamá, ¿por qué es mejor el egoísmo de tres que el egoísmo de uno?".

Dicha pregunta, si se le mira con cuidado, va más allá de un asunto puramente circunstancial y pone en entredicho uno de los criterios éticos más reconocidos, el del utilitarismo, que supone que lo que está bien es aquello que lleva a una mayor cantidad de felicidad (en el sentido de mayor disfrute de placeres con menor costo) para la mayoría de las personas implicadas; pues lo que subyace a la pregunta de este niño es el interrogante de si el criterio meramente numérico establece una diferencia moral efectiva (es decir, hace ciertamente mejor) entre dos cosas que son semejantes, es decir, dos formas de egoísmo, la de él y la de sus compañeritos. ¿Es el número un factor que tenga relevancia ética? ¿Podemos estar seguros de que es necesariamente mejor lo que desea un mayor número de personas que lo que desea una minoría? ¿Tiene la regla de la mayoría un valor efectivamente ético, más allá de que pueda ser un mecanismo legítimo para resolver conflictos de poder o incluso de convivencia? Pocas cosas logran poner en entredicho de forma tan clara el criterio moral utilitarista como esta pregunta, a la vez ingenua y demoledora, de un niño.

Si he puesto un cierto énfasis en el anterior ejemplo es precisamente porque nos muestra cómo los niños pueden, a partir de situaciones simples de su vida cotidiana, llegar a plantearse no sólo interrogantes prácticos ligados a sus acciones concretas, sino incluso preguntas éticas fundamentales. El asunto, sin embargo, no se detiene allí. Los niños, más allá de la enseñanza directa que nosotros podamos darles sobre ciertos valores, construyen formas de valoración para sus acciones y las de otros, y desde el principio empiezan a calificar sus acciones y las de sus compañeros como justas o injustas, buenas o malas, correctas o incorrectas. ¿Por qué no, en vez de enseñarles nociones abstractas sobre supuestos "valores", aprovechar aquellas situaciones que ellos califican con términos que tienen una clara connotación valorativa para empezar, mediante preguntas elementales, a examinar cuáles son las razones que tienen o el tipo de criterios que aplican a la hora de usar tales calificativos? Tal vez ello no solo sirva para que adquieran mayor confianza en sus propios poderes cognitivos, o para promover un diálogo reflexivo en el salón de clases, sino incluso para que los propios niños se aventuren en la investigación ética, es decir, en el examen riguroso y persistente de todos los factores determinantes de la acción moral. 
Me pregunto, a estas alturas, si no será posible invertir radicalmente la perspectiva en que abordamos ordinariamente el problema de la educación moral de los niños. Puesto que los adultos siempre creemos que tenemos algo que enseñarles en cuestiones de moralidad, ¿por qué no tomar ahora otro punto de partida: el de sus propios aprendizajes morales? Puesto que creemos tener ya las soluciones correctas a los problemas que les aquejan, ¿por qué no, más bien, darles la ocasión para que examinen los factores que entran en juego en una situación moral y permitirles que exploren alternativas diversas de acción antes de asumir la decisión que parece "correcta" simplemente porque es la que satisface a los adultos? Puesto que creemos estar seguros de lo que significan conceptos morales tan fundamentales como bondad o justicia, ¿por qué no dejar que ellos los examinen ligados a circunstancias concretas y que vayan comprendiendo el significado de tales conceptos y ampliándolo a partir de su propio examen reflexivo?

Cuando propongo invertir la perspectiva dentro de la cual nos ocupamos de la educación moral de los niños no lo hago dentro del espíritu de una "duda metódica" que tiene por fin demostrar que, finalmente, éramos los adultos quienes teníamos razón y, por tanto, nada mejor podrán hacer ellos que seguir nuestras orientaciones. No, precisamente la posibilidad de una nueva educación moral radica de una forma definitiva en que confiemos seriamente no sólo en los poderes cognitivos de los niños, sino, sobre todo, en su capacidad para desarrollar una reflexión ética a la vez abierta, rigurosa y pluridimensional.

Lo que ofreceré a continuación es un primer esbozo de una propuesta que, con tal fin, he venido desarrollando hace algunos años y que tiene su primera expresión en mi pequeño libro El miedo es para los valientes y otros cuentos para la reflexión ética. Quiero insistir, antes de hacer el esbozo general de mi propuesta, en que es algo que apenas está empezando a desarrollarse, que se trata de un proyecto en construcción que apenas está pasando por una fase experimental.

\section{Hacia un programa de educación moral en perspectiva filosófica: primeros esbozos}

He usado con anterioridad la expresión "factores determinantes de la acción moral”. ¿A qué me refiero con ella? Cuando examinamos nuestras acciones con el fin de hacer juicios valorativos sobre ellas (en esto consiste precisamente la reflexión ética) debemos tomar en cuenta una serie de factores que son los que dan sentido y una posible justificación al tipo de acción emprendida. Examinar las acciones en orden a su valoración ética supone, entre otras cosas, a) examinar cada una de las circunstancias (qué, quién, cómo, cuándo, dónde, para qué, con qué medios, etc.) en que tuvo lugar dicha acción; b) hacer explícitos y valorar los motivos que dieron lugar a que emprendiera cierta acción; c) imaginar las posibles consecuencias que se seguirían de actuar de una u otra forma, y d) ofrecer las mejores razones posibles en una circunstancia dada en orden a justificar la manera de actuar elegida.

Por lo menos estos cuatro factores (circunstancias, motivos, posibles consecuencias y razones de la acción) podrían ser analizados con algún detalle por los propios niños, y esto sería un punto de partida esencial para desarrollar en ellos una capacidad básica de reflexión ética. No digo que en ello radique toda la reflexión ética, pues también incluye otros aspectos, como la búsqueda de criterios y reglas para la acción, el examen de los principios que seguimos a la hora de actuar, o incluso la consideración de las emociones que están implicadas en cada uno 
de nuestros juicios valorativos. Sin embargo, en el examen de estos factores determinantes de la acción hay ya un punto de partida básico para que los niños, en vez de que siempre esperemos de ellos que se limiten a memorizar reglas o a asimilar nuestra enseñazas moralizantes y abstractas, estén en condición de examinar las situaciones de su vida cotidiana y de identificar en ellos cada uno de los factores que le otorgan a nuestras acciones un sentido y una posible justificación.

Lo que pretendo defender, como puede verse, es que no puede haber una auténtica educación moral sin el examen detenido de los múltiples interrogantes filosóficos que nos suscitan cada una de las situaciones morales en que nos vemos envueltos y las decisiones que a cada instante de nuestra vida nos vemos obligados a tomar. No es suficiente con "clarificar nuestros valores", mejorar en "la toma de decisiones" o "perfeccionar nuestro razonamiento en cuestiones morales", como lo pregonan los programas de educación moral en boga.

Corremos el riesgo de reducir la educación moral a la presentación y enseñanza, a menudo dogmática, de "valores" prefijados sin que se haga nunca un examen crítico de ellos y sin que ni siquiera se ponga en cuestión lo que significan cada uno de esos "valores" o la idea misma de que hay "valores" en el sentido de ideas prefijadas de lo que es bueno para nuestra vida personal; o, a cambio de ello, podemos terminar, también, promoviendo un ingenuo relativismo donde cada uno "aclara" y "defiende" sus valores basado en el mero capricho, gusto o inclinación, sin tomarse ni siquiera el trabajo de preguntarse, a la manera de Nietzsche, en qué radica "el valor" de tales valores. Corremos también el riesgo, al poner el acento en la "toma de decisiones", según un estilo gerencial, de perder de vista el conjunto del proceso de investigación moral y centrarnos solamente en su estado final, dejando de lado todos los múltiples aspectos que preparan y hacen razonable una decisión moral. O podemos, finalmente, terminar por reducir, cuando asumimos como un enfoque absoluto el del razonamiento sobre dilemas morales, la educación moral a un entrenamiento cognitivo en el examen de las situaciones, dejando de lado los aspectos afectivos que modelan y modulan nuestro juicio moral y que determinan la percepción que tenemos de las situaciones morales en que nos vemos continuamente involucrados.

Pretendo, pues, defender la tesis, ya sugerida por Lipman y Sharp, de que una auténtica educación moral es inseparable de la investigación filosófica ${ }^{4}$, de que esto es posible y deseable comenzarlo desde los primeros años de la infancia y de que tal trabajo sólo puede realizarse de forma efectiva si se invita a los niños y jóvenes a examinar, explorar alternativas y evaluar, en el marco de una comunidad de indagación filosófica, tanto las situaciones morales en que se encuentran comprometidos como sus propios intereses, emociones y creencias como factores relevantes de dichas situaciones.

Como ya lo había insinuado a propósito de mi referencia a Aristóteles, el aprendizaje moral no es un aprendizaje meramente teórico. No se aprende "ética" del mismo modo que se aprenden ciencias como las matemáticas, la física o la biología. En estas ciencias lo esencial es el conocimiento de ciertas verdades que la humanidad en su desarrollo ha ido consolidando en su intento por comprender el mundo de forma más racional. La comprensión ética, en cambio,

\footnotetext{
${ }^{4}$ Cfr. Lipman, Sharp and Oscanyan: Philosophy in the Classroom. Philadelphia: Temple University Press, 1980, pp. 153-187.
} 
tiene que ver no tanto con el aprendizaje de reglas y principios abstractos como con el proceso de reflexión sobre nuestras propias acciones a la luz de ciertos criterios (como los factores antes mencionados) que nos ayuden a entender por qué valoramos como mejores ciertos actos que otros y cuáles son las razones fundamentales de ciertas valoraciones. El aprendizaje ético no pretende formar personas más instruidas en temas morales, sino propiciar la formación de personas más razonables, es decir, de personas que son capaces de dar razones, de pedir razones y de evaluar aquellas razones que se dan y se ofrecen en orden a justificar sus formas de actuar.

Si nos atrevemos a afirmar que el niño puede ser un sujeto de reflexión ética es porque consideramos que está en condiciones de examinar sus acciones a la luz de los criterios señalados, y sobre todo porque creemos que su educación ética no debe reducirse a la simple asimilación de reglas y principios que muchas veces resultan completamente ajenos a su experiencia. En vez de atosigarlos con un discurso moral abstracto, con una prédica sobre "los valores”, ¿por qué no intentar encontrar un camino por medio del cual ellos mismos, y a partir de situaciones que viven en su experiencia diaria, puedan, después de un examen riguroso, descubrir por sí mismos qué es lo que hace que una acción sea mejor que otra, o por qué ciertas situaciones resultan justas o injustas?

Algo de este estilo es lo que yo mismo he intentado a través del citado pequeño texto El miedo es para los valientes y otros cuentos para la reflexión ética. Se trata de una serie de historias que los niños pueden leer y discutir entre sí, y con el apoyo de los adultos, en las cuales un niño relata algo que le aconteció y, a propósito de ello, va haciendo sus propias reflexiones sobre la situación que vive y lo que en ella le resulta interesante y problemático desde un punto de vista ético. Los temas que allí se abordan, en un lenguaje perfectamente asequible para los niños de la educación básica primaria, son muy diversos: la crueldad, el sentido y las implicaciones del acto de mentir, el significado de una virtud moral como la valentía, los criterios a partir de los cuales calificamos una acción o una situación como justa, etc. A partir del relato y el examen de cada una de las situaciones presentadas en estas historias, los niños pueden plantearse sus propias preguntas y elaborar argumentos que les ayuden a comprender mejor el sentido de sus actos y la valoración que estos merecen.

\section{Un ejemplo de reflexión ética en torno al significado de una virtud moral: El miedo es para los valientes}

Para concluir, ofreceré un ejemplo específico de cómo es posible empezar a desarrollar una educación moral de carácter reflexivo, filosófico, en la escuela primaria. Por supuesto, el ejemplo no pretende decir qué es lo que habrá de ocurrir en una "clase de ética" en la escuela primaria, pues todo lo que aquí se ofrece es un texto narrativo como punto de partida y algunas observaciones teóricas a propósito de diversos problemas filosóficos que podrían surgir a propósito del examen y discusión de la historia propuesta.

Lo que pueda o deba suceder a propósito de la lectura y comentario de la historia que se ofrece a continuación es algo que deberán determinar los propios estudiantes junto con su maestro, y no alguien que esté situado por fuera del ámbito de la discusión, ni siquiera aquel que funge como "autor" del cuento. Lo que quiero subrayar, entonces, es que no existe ninguna interpretación oficial de la historia, ni siquiera la que pudiera ofrecer el propio autor 
en el manual para el maestro que sirve de apoyo al profesor para trabajar en clase con él. Los niños deben, por tanto, explorar la historia libremente y discutir aquellos temas que, a propósito del relato (aunque no necesariamente tal como se plantean el relato), suscitaron su interés reflexivo.

A lo mejor algunos querrán indagar mucho más a propósito del significado de una emoción tan propia de cada uno de nosotros como el miedo. Tal vez otros quieran examinar las relaciones existentes entre una emoción como el miedo y una virtud como la valentía. Es posible que otros pretendan indagar por la validez de una definición como la que se sugiere allí sobre la valentía. A otros puede interesarles más bien un examen cuidadoso del acto de llorar y su significado, o profundizar en nociones como "fuerza", "cobardía", "tranquilidad" o "solidaridad". En fin, son los propios niños los que deben plantear la agenda de discusión, buscar las mejores razones para lo que dicen, examinar los argumentos propios y de sus compañeros, examinar las circunstancias de los actos que someten a examen, prever las consecuencias posibles de un determinado acto que pudieran emprender o examinar la validez de los motivos que en un cierto momento pudieran llevar a una persona a actuar de una determinada forma. Al maestro le corresponde ser alguien que comparte con ellos el proceso de indagación planteando nuevas preguntas, sugiriendo posibles situaciones para el análisis, ayudándoles a explorar más a fondo los conceptos con los que trabajan y, especialmente, permaneciendo vigilante para que las condiciones que hacen posible el diálogo y la investigación filosófica no sean alteradas por brotes de violencia, intolerancia o argumentación erística.

Como ya quedó insinuado en el párrafo anterior, la historia que he elegido en este caso como ejemplo es el cuento El miedo es para los valientes. Aunque tal elección es, en cierto modo, arbitraria, pues podría haber elegido otros textos (míos o de otros autores), hay algunas razones para tal escogencia. En primer lugar, se trata de una historia que se ocupa de una noción muy fundamental en la reflexión ética clásica, la de una de las principales virtudes morales: la valentía. En segundo término está el hecho de que la historia está construida como resultado de un esfuerzo propio por esclarecer la noción de valentía, que tiene su origen en un estudio muy detallado que por entonces hacía por reconstruir, después de un examen minucioso, la concepción de valentía que hay en la Ética nicomaquea de Aristóteles. En tercer término, puedo decir, entonces, que esta historia es el resultado de pensar un problema filosófico (el del significado del concepto de valentía) metido en la mente de un niño imaginario (que, tal vez, sea yo mismo) que vive circunstancias que lo obligan a plantearse los problemas que allí aparecen. En tal sentido, es importante, entonces, tener en cuenta que toda la historia es una especie de autorreflexión que hace un personaje-niño en donde, a propósito de circunstancias que podría vivir cualquier niño de su misma edad, se plantea una serie de reflexiones éticas que resultan pertinentes en su esfuerzo por comprender y dar un significado a su experiencia.

Invito, pues, al lector, para que a continuación dé una lectura completa a la historia, antes de que me ocupe, como me ocuparé más adelante, de examinar algunos de los problemas y conceptos filosóficos fundamentales que allí aparecen "flotando" en medio de la narración.

El miedo es para los valientes 
Cuando vi que mi mamá entró a la sala de operaciones no pude evitar ponerme a llorar. Pedro, mi hermano mayor, se acercó y me dijo:

- No llores, Santi. Verás que todo va a salir bien.

- Sí, yo sé que todo va a salir bien. Pero mi mamá va a sufrir, y eso me da mucho miedo.

- Sí, es cierto. Pero tú no debes llorar. Los hombres somos valientes. Las que lloran son las niñas.

- ¿Y tú nunca has llorado? -fue lo único que se me ocurrió preguntarle.

- Bueno, nunca tampoco... -me respondió.

Sentí como si fuera a contarme algo muy importante para él, pero no se atrevió. A lo mejor pensó que yo era todavía muy niño y que no iba a entenderlo. Sin embargo, yo sé que él sí ha llorado. Y seguramente lo ha hecho muchas veces.

Me acuerdo que hace como seis meses entré un día en su cuarto y estaba llorando. Él intentó mostrarme que no le pasaba nada... pero yo sí sabía que algo le pasaba. Dos días después supe que había peleado con su novia. ¡Lástima! Catalina, su novia, era una muchacha muy linda... y muy querida.

Sé que mi pregunta lo sorprendió. No se la esperaba. Pero yo soy su hermano y no le resulta fácil ocultarme las cosas cuando compartimos el mismo cuarto. Yo, por lo menos, lo he visto llorar una vez, que me acuerde... pero, seguramente, debe haber llorado muchas veces.

No veo problema en eso. Todos lloramos: él, yo... y seguramente todas las demás personas, hombres y mujeres. ¿Por qué viene a decirme, entonces, que no debo llorar sólo por el hecho de que soy hombre?

Después de un rato se me volvió a acercar, cuando yo ya estaba un poco más tranquilo, y, mientras seguíamos esperando a que terminara la operación de mi mamá, me dijo:

- $\quad$ Lo que te he querido decir es que debemos ser valientes.

- $\quad$ ¿Y, si lloro, no soy valiente? -le respondí.

- No necesariamente. Hay personas valientes que lloran.

- ¿Y esas personas son hombres o mujeres?

- Da lo mismo. Tanto los hombres como las mujeres lloramos. Y tanto unos como otros podemos ser valientes.

- Pero, ¿para ser valientes es necesario no llorar?

- No, no creo...

- Pero antes me dijiste que no debía llorar, sino que tenía que ser valiente, y que son las niñas las que lloran, no los hombres como tú y yo.

- Sí, es cierto. Eso fue lo que te dije. Pero, la verdad, no es eso lo que pienso. Es sólo algo que aprendí a decir porque a mí también me lo decían cuando tenía tu edad. Pero, ahora que me lo preguntas, creo que eso no es correcto.

- ¿Qué es lo que no es correcto: llorar o decir esas cosas?

- Bueno, debe haber muchas cosas que no son correctas. Pero seguramente llorar no sea una de ellas.

- Entonces llorar no es necesariamente algo malo.

- Claro que no.

Creo que ahora empezaba a comprender un poco mejor a mi hermano Pedro. En realidad, él tampoco creía que ser valiente tuviera algo que ver con llorar o dejar de hacerlo. Además, yo veía que él también estaba preocupado, y que todo lo que había hecho era intentar tranquilizarme. 
Además, de hecho, yo ya estaba un poco más tranquilo. Hubo muchas cosas que me ayudaron a tranquilizarme. Estuve pensando en que nadie se ha muerto de una operación de apendicitis, que mi mamá siempre ha sido una persona fuerte y que tiene buena salud, que mi papá la estaba acompañando en la sala de operaciones y que los médicos de este hospital son muy buenos médicos.

Sentí, además, que Pedro no me abandonaría. Aunque a veces dijera cosas con las que yo no estaba de acuerdo, sentía que él me estaba acompañando. Y a lo mejor él también se sentía acompañado por mí.

Durante el tiempo que estuve esperando allí pude pensar en muchas cosas. Sobre todo después de que logré tranquilizarme. De lo que había hablado con Pedro había especialmente una pregunta que me inquietaba: ¿qué será, entonces, ser valiente?

Debe ser lo opuesto a ser cobarde. Pero, ¿a quiénes llamamos cobardes? A los que lloran algunas veces, a los que sienten miedo otras, a los que no se atreven a hacer algo, a los que no son fuertes para enfrentar los problemas.

Si eso fuera así, entonces el valiente sería el que no llora, el que no siente miedo, el que se atreve a hacer las cosas y el que es fuerte. Pero, no sé, ahí había algo que no me convencía. A lo mejor alguien puede ser valiente y llorar y sentir miedo... y otras cosas. Y a lo mejor también hay personas cobardes que son fuertes, o por lo menos lo parecen.

El otro día vi a un señor borracho en una tienda buscándole pelea a otros. Se sentía muy fuerte y quería, él solo, enfrentarse con los demás. Pero, si se sentía tan fuerte, ¿por qué necesitaba emborracharse para demostrar su fortaleza? Lo estuve pensando y me pareció, más bien, una persona cobarde. Aunque era fuerte, porque vi que le pegó a una persona y le dejó un ojo morado.

Cuando estaba pensando en esto apareció mi papá. Nos dijo que la operación de mi mamá había salido muy bien y que no teníamos de qué preocuparnos. Nos dijo también que ella ya estaba en recuperación y que antes de dos horas podríamos estar en su cuarto acompañándola.

Eso me tranquilizó mucho. De todas maneras ya no estaba intranquilo. El tiempo que tuve para pensar me ayudó mucho para tranquilizarme.

Mi papá me invitó a la tienda de en frente a tomarme un jugo. Él pidió una cerveza. Mientras nos la tomábamos no pude resistirme a hacerle la pregunta.

- Papá, ¿qué es ser valiente?

- No lo sé exactamente. Es difícil definirlo. Pero, si lo que quieres es que te diga lo que creo que es ser valiente, te diría esto: ser valiente es hacer lo que uno sabe que debe hacer a pesar de todo el miedo que tenga.

- Entonces, papá, uno puede tener miedo y ser valiente.

- Sí, claro.

- ¿Y, si uno no tuviera miedo, no sería valiente?

- Tal vez no.

- ¿Y hay personas que no sientan miedo?

- Sí, yo creo que hay personas que no sienten miedo. A veces simplemente porque no se dan cuenta de lo que puede pasar, y otras veces porque se han preparado para 
controlar el miedo que sienten.

- Pero, papá, se trata de dos cosas distintas. Si a uno no le da miedo porque no se da cuenta del peligro o de lo malo que le puede pasar, eso es gravísimo. Es mejor sentir miedo, porque el miedo es como una señal que uno siente en el cuerpo de que hay un peligro o de que algo malo puede pasarle. Pero hay otra gente cuya vida es vivir en peligro permanente, como los soldados y los automovilistas. Ellos se preparan para dominar el miedo.

- Pero no todos los miedos, sino sólo algunos. Una vez conocí a un soldado que había participado en varias guerras y que había combatido con la guerrilla en la selva muchas veces. Tenía unos nervios de acero. Y, sin embargo, apenas vio un ratón en el sitio en el que estábamos se puso a gritar y se montó encima de una mesa muy angustiado. ¿Tú qué crees: ese era un hombre valiente o cobarde?

- No lo sé. A lo mejor las dos cosas.

- No, uno no puede ser valiente y cobarde al mismo tiempo. O lo uno o lo otro.

- Pero sí puede ser valiente en unas situaciones y cobarde en otras. Ese soldado era valiente en la guerra, pero lo dominaba el pánico cuando veía un simple ratoncito.

- Claro: ese es el punto importante. Una persona valiente puede tener miedo, pero no se deja dominar por el miedo.

- Papá, yo sentí mucho miedo cuando entraron a mi mamá a la sala de operaciones. Incluso me puse a llorar y Pedro trató de consolarme. ¿Crees que me comporté de una forma cobarde?

- ¿Te sirvió de algo haber llorado?

- Si, la verdad, después de llorar, me sentí más tranquilo.

- Entonces te sirvió para dominar el miedo.

- A lo mejor sí. Pero no fue sólo eso. También me ayudó hablar con Pedro y estar un rato solo pensando. Y también me tranquilizó saber que mi mamá estaba bien. Y ahora me ha ayudado muchacho haber hablado contigo.

- Hiciste lo que debías hacer: esperar. Hay momentos en que no se puede hacer otra cosa. Y supiste esperar, sin dejarte dominar por el miedo que a lo mejor sentiste en algún momento.

- Sí, pero hubo un momento en que flaqueé un poco y me puse a llorar.

- ¿Y eso marca alguna diferencia? ¿Habrías sido más valiente si no hubieras llorado en ningún momento?

- Creo que no. Pero a veces no me gusta hacerlo en público.

- Pero había un buen motivo para hacerlo: tu mamá. Yo hubiera querido poder llorar tranquilo, porque también estuve muy angustiado antes de empezar la operación. Pero necesitaba mostrarme fuerte: por ella, por tu hermano... y por ti. Ahora déjame solo. Ve al cuarto de tu mamá y la esperas. Creo que voy a ir al baño y me voy a encerrar un rato allí para estar más tranquilo. Si voy a llorar o no... nunca lo sabrás.

Lo dejé tranquilo. Fue un rato muy agradable.

Después de esperar algo más de una hora, pude ver a mi mamá cuando la llevaban al cuarto. Esta vez también lloré. Pero ahora nadie me dijo que no fuera valiente. Pedro se acercó, me abrazó (esta vez él también estaba llorando) y me dio un par de palmadas en la espalda.

Luego nos acercamos a la camilla en que llevaban a mi mamá. Todavía estaba dormida, pero se le veía bien. Había sufrido. Seguramente también habría pasado momentos de angustia. Pero hizo lo que debía hacer. No sé a quién se le habría ocurrido la idea absurda de que las mujeres no son valientes. 
A mí lo único que me da miedo en este momento es el dolor tan fuerte que voy a tener el día en que me operen de apendicitis.

Hay, por supuesto, en esta historia un tema central: el del significado de la valentía como virtud moral y el de la relación que existe entre ella y una emoción específica: el miedo. Hay, además, desde luego, una tesis implícita (aunque el título mismo de la historia la hace explícita): que la valentía no radica en no tener miedo, sino en aprender a dominarlo, entendiendo, desde luego, que "dominarlo" no quiere decir algo así como reprimirlo, suprimirlo o sublimarlo, sino actuar sin que el miedo se convierta para nosotros en una fuerza paralizante que nos impide hacer lo que creemos que debemos hacer.

De esa manera de entender la valentía se sigue, además, una peculiar comprensión del significado de una emoción como el miedo, expresada en la idea de Santi según la cual el miedo cumple una función específica: la de ser una especie de señal que sentimos en nuestro cuerpo de que hay un peligro posible, un mal latente, y que, por tanto, debemos actuar con cautela. De hecho, aquí el miedo no aparece como algo que impida ser valiente, sino como la condición misma de la valentía, pues no se puede ser valiente sin experimentar el propio miedo.

En el cuento hay, pues, una idea ética rectora, puesto que pretende cambiar la percepción que solemos tener de nuestro propio miedo y sugerir una manera más razonable de comprenderlo. El solo título, por cierto, ya lo insinúa: el miedo es para los valientes. Recuerdo ahora algo que me sucedió hace unos años con esta historia. En una oscura noche en una carretera me detuvo el ejército colombiano a hacerme una requisa y, en el asiento trasero de mi carro, había un ejemplar del libro. El soldado leyó el título: El miedo es para los valientes. Inmediatamente se sorprendió y me pidió que se lo regalara. Cuando me preguntó quién era su autor y le dije que era yo (al principio no me creía y me tocó identificarme), inmediatamente me dijo lo siguiente:

Soy soldado profesional y llevo muchos años combatiendo en el monte en condiciones muy difíciles. Siento miedo permanentemente y tengo que aguantármelo. No se lo puedo confesar a nadie porque me dicen que soy un cobarde. A mí me han enseñado siempre que ser valiente es no tener miedo... y, sin embargo, lo siento a cada instante. No he leído su libro, pero me ha hecho pensar con el solo título en que no soy un cobarde como creía hasta ahora. Tal vez sentir miedo no sea tan malo como siempre me lo han dicho.

Esta idea rectora del cuento, no es, sin embargo, todo lo que allí puede encontrarse. Además, esta idea rectora no debe entenderse como una especie de moraleja que deba ser aprendida como una verdad indiscutible por su lector. De hecho, las ideas, las imágenes y los casos que propone la historia son para examinarlos y discutirlos a fondo y no para asimilarlos como una especie de "verdades morales fundamentales". Es posible que alguien se rebele contra esta idea rectora y proponga una manera muy diferente de entender la valentía. Ello es válido y deberá existir el espacio y el tiempo para discutirlo. También es posible que alguien no comparta la definición de valentía que nos ofrece el papá de Santi, o que encuentre un ejemplo mejor que los que encuentran Santi y su papá para examinar la pregunta que se han planteado. Todas ellas son posibilidades que caben en un ejercicio de reflexión filosófica que sea efectivamente libre y abierto. 
Junto a la idea fundamental ya señalada, hay en esta historia muchos otros asuntos éticos y filosóficos que podrían examinarse y a los que quisiera hacer también alguna referencia a continuación. Empezaré por enumerar trece núcleos de reflexión fundamentales que, solamente para este cuento, he identificado en el manual de apoyo para el profesor, que acompaña esta historia y que lleva por título Buscando alternativas para la acción. Allí el maestro que trabaja esta historia con un grupo de niños encontrará algunas orientaciones básicas para conducir el diálogo y para propiciar la reflexión de los niños, consistentes en una serie de comentarios sobre cada pasaje del texto, en planes de discusión que pueden ayudar a examinar con mucho mayor rigor algunos de los problemas que posiblemente habrían de plantearse tras su lectura y en algunas actividades y ejercicios que ayudan a clarificar conceptos, a examinar situaciones, a hacer juicios morales de diversa índole, etc. Los trece núcleos de reflexión básicos identificados en el manual de apoyo del maestro son los siguientes:

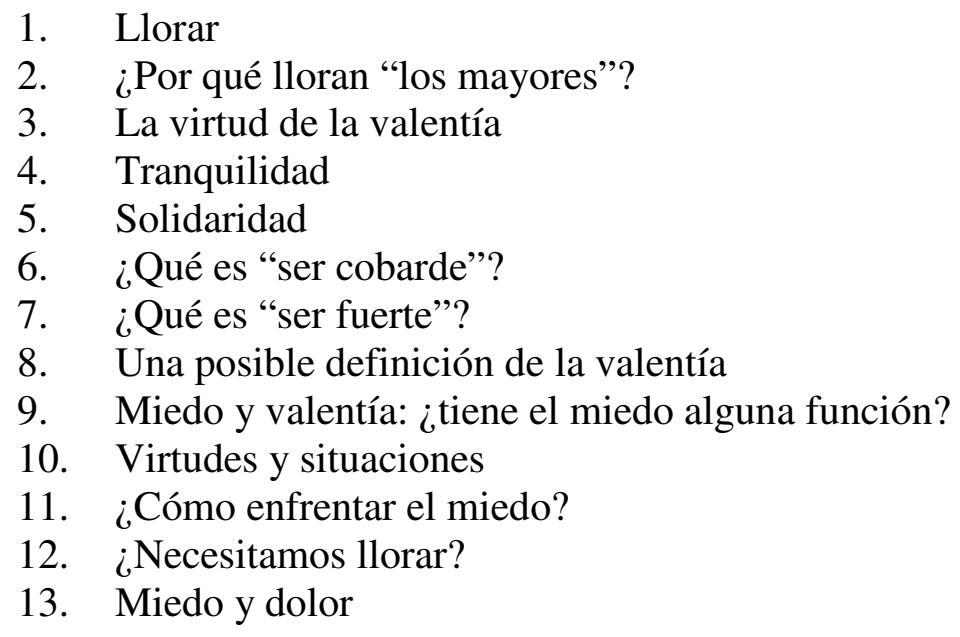

Estos son solo algunos de los temas básicos que yo, como autor, he identificado con precisión en la historia y los que sirvieron de base para la composición del manual para el maestro. Los niños que examinan y discuten esta historia descubren con frecuencia en ella muchos otros asuntos que despiertan su interés, y los maestros que trabajan con ella deben estar siempre dispuestos a ayudarles a examinar ese tipo de problemas, en vez de pretender coaccionar su interés hacia unos temas o problemas prefijados. Seleccionaré a continuación solo cuatro de estos temas para hacer un breve comentario sobre ellos.

El acto de llorar: en pocas cosas somos tan iguales los hombres como en el hecho de que hay cosas que nos producen tal angustia que nos llevan a llorar. Éste, que es uno de los actos más comunes y elementales de nuestra vida, es, sin embargo, muy pocas veces objeto de reflexión. ¿Qué es lo que significa el acto de llorar? ¿Llorar implica siempre un acto de cobardía o va necesariamente acompañado de un sentimiento de tristeza? ¿Es necesariamente un signo de debilidad o afeminamiento o puede también, bajo determinadas circunstancias ser una muestra de fortaleza y solidaridad? ¿Lloran sólo las mujeres y los niños? ¿O lloran también los adultos varones? Si es así, ¿por qué lo hacen y qué es lo que significa su llanto? Plantearse interrogantes de este estilo y discutirlos abiertamente con los demás compañeros puede ser altamente liberador para los niños; y más aún si lo hacen en presencia de un adulto como su maestro. Para éste, a su vez, puede resultar muy enriquecedor compartir estos asuntos 
con sus estudiantes. Desde el punto de vista filosófico, un análisis cuidadoso de un acto como éste puede ser tremendamente iluminador si se entiende que también la filosofía se ocupa de las emociones y el dolor humano y de la búsqueda del significado de los diversos actos humanos.

La virtud de la valentía: todo este cuento constituye una reflexión en torno a eso que ya desde la antigüedad griega se conoció como "la valentía" y que, desde entonces, fue catalogada como una virtud. Una virtud, según la definición más clásica de ella -la que nos da Aristóteles-, es "un hábito digno de elogio", es decir, una cierta forma habitual (no meramente ocasional) de comportarse que merece el elogio de los demás (no solo que es elogiada, pues, de hecho, elogiamos muchas cosas que no son dignas de elogio, como la vanidad o la ambición). Para que una determinada forma de actuar pueda ser considerada virtuosa se requieren al menos tres condiciones básicas: a) que conduzca hacia la realización de una obra que objetivamente podamos decir que es buena; b) que favorezca el perfeccionamiento de la persona que obra, y c) que el bien que esa forma de actuar procura sea un bien para otros, y no solo para quien actúa. De esta forma, por ejemplo, consideramos que la generosidad es una virtud en el sentido de que los actos generosos tienden a producir obras buenas, hacen mejores a quienes practican este tipo de actos y procuran un bien para quienes son receptores de un acto de generosidad. Al igual que la generosidad, hay muchas otras virtudes que requieren de un análisis más detallado: la solidaridad, la lealtad, la paciencia, la prudencia, la justicia, etc. La discusión en torno al significado y contenido de las virtudes es uno de los aspectos centrales de la reflexión ética, y es esencial iniciar a los niños desde muy pequeños en la reflexión en torno a la naturaleza y significado de las virtudes y prepararlos para que puedan evaluar sus actos y los de otros a la luz de estas nociones éticas tan fundamentales. En las múltiples "tablas de virtudes" que podemos encontrar en la historia de la reflexión ética, desde la misma antigüedad griega, es esta una virtud fundamental. Aunque en ocasiones se le ha tendido a confundir con la mera "hombría", la fortaleza física o el coraje para la batalla, la verdad es que se trata de una virtud que tiene un contenido mucho más amplio, que tiene que ver con una cierta fortaleza interior que se requiere para emprender las diversas acciones de la vida, a pesar de los muchos peligros y amenazas que estas nos presentan. En su sentido original tiene que ver especialmente con la capacidad que tenemos para enfrentar una de las emociones humanas más básicas, la del miedo. Como bien dijo Platón, éste consiste "en la expectativa de un mal futuro". Pues bien, ser valiente se refiere muy específicamente al modo como habremos de enfrentar el miedo, y toda la reflexión que se hace en esta historia se ocupa del modo como Santi fue capaz de enfrentar la operación de apendicitis que, de repente, tuvo que enfrentar su madre. Valdría la pena examinar algunas de las preguntas de Santi con los propios niños para ver qué piensan de ellas. ¿Qué es ser valiente? ¿Necesitamos ser valientes en todas las circunstancias? ¿Hasta qué punto la valentía depende de la fuerza que tengamos? ¿Debemos dominar el miedo para ser valientes? ¿Llorar nos ayuda a ser valientes o nos impide serlo? ¿También los niños pueden ser valientes o eso es sólo algo de los mayores? ¿Son valientes de la misma forma hombres y mujeres? Estos son solo algunos de los interrogantes más básicos que genera un examen minucioso de esta virtud fundamental, y este cuento ofrece distintas ocasiones para examinarlas.

${ }^{5}$ Laques, 198 b. 
Las relaciones entre miedo y valentía: ¿tiene el miedo alguna función?: en el diálogo que Santi tiene con su papá, discuten sobre las relaciones que existen entre el miedo y la valentía. Santi plantea la hipótesis de que uno puede al mismo tiempo ser valiente y tener miedo y que, en cierto sentido, sentir miedo es una condición para ser valiente, pues quien no tiene miedo y no se ve obligado a superarlo no es valiente, sino temerario (recordemos que ser osado o temerario es otro extremo de la valentía, el extremo opuesto a la cobardía), pues ser valiente implica sobreponerse al miedo que uno tiene. ¿Por qué es así? Porque cuando no se siente miedo no se tiene una clara conciencia de los peligros que se enfrentan y, por ello mismo, nuestra acción tiende a volverse azarosa e irracional, y una acción valiente es razonable e incluso en muchos casos debe estar muy bien planificada. Después de que han reconocido, junto con su padre, que hay personas que pueden no sentir miedo, Santi se da cuenta de que ello puede ser, además de grave, muy peligroso, pues el miedo, así lo explica Santi, "es como una señal que uno siente en el cuerpo de que hay un peligro o de que algo malo puede pasarle". Parece entonces que, según Santi, el miedo cumple una función positiva en nuestras vidas, pues sirve para ponernos alerta ante los peligros y amenazas que pueden sobrevenir sobre nosotros. El problema, entonces, no parece ser el de si se trata de tener o no tener miedo. Más bien sería el de qué hacemos con el miedo, cómo lo manejamos. Un miedo que nos paraliza es ciertamente dañino, porque nos impide actuar. Un miedo que nos previene y nos obliga a actuar con cautela es indispensable para que nuestra acción sea prudente y no se vaya al traste por la imprevisión o la precipitación. ¿Tiene sentido, entonces, que nos preparemos para no sentir miedo? No mucho, pero puede tener sentido que nos preparemos para dominar el miedo, pues hay cierto tipo de actividades que entrañan un riesgo inminente, en las que está siempre en juego la vida, que implican que, en momentos de sumo peligro, sepamos actuar con mucha serenidad manteniendo el miedo bajo control. Santi nos sugiere dos de esas actividades que implican aprender a dominar el miedo: la de los soldados y la de los automovilistas. Sin embargo, no son solo los soldados y automovilistas quienes deben prepararse para dominar el miedo. También debemos hacerlo todos los demás. Sin embargo, el papá de Santi nos sugiere algo interesante: que no existe el miedo en general, sino miedos específicos. Los niños experimentan muchos de ellos: a la oscuridad, a las brujas, a los animales salvajes, a la pobreza económica, etc. ¿Puede uno aprender a dominar todos estos miedos al mismo tiempo? Parece que no. El papá de Santi nos sugiere que uno se prepara para enfrentar miedos específicos (el soldado el miedo al combate, el automovilista el miedo a las altas velocidades), pero no el miedo en general, y nos ilustra lo anterior con el ejemplo del soldado que no podía dominar su miedo a los ratones a pesar de que venía de los horrores más terribles de la guerra. Es muy importante poder discutir todos estos ejemplos con los niños, para ver cómo los interpretan ellos. A propósito del examen de tales ejemplos, los niños irán clarificando poco a poco el concepto de la valentía mediante el esfuerzo de pensar por sí mismos.

Virtudes y situaciones: las virtudes son buenas por definición, pero saber si una acción o una persona son virtuosas implica analizar situaciones específicas. Nadie duda, por ejemplo, que sea bueno ser solidario, pero puede poner en entredicho si una determinada forma de actuar es o no una efectiva muestra de solidaridad. El papá de Santi, por otra parte, ha puesto de presente que seguramente uno no puede controlar el miedo en general, sino miedos específicos, como el miedo a las alturas, a la oscuridad, a la velocidad, al combate armado, etc. Para comprender mejor esto ha citado el ejemplo del soldado "con nervios de acero" que le tiene miedo a un ratón. El análisis de situaciones distintas es una de las mejores 
formas que tenemos para explorar el significado de las virtudes. A propósito del ejemplo del soldado, su papá le pregunta a Santi si este era un hombre valiente o un hombre cobarde. Santi cree que aquí no vale una respuesta absoluta, pues, si bien uno no puede ser valiente y cobarde (es decir, no-valiente) al mismo tiempo, pues ello viola un principio lógico tan elemental como el de la no-contradicción, es posible ser valiente en unas situaciones y cobarde en otras, es decir, uno puede ser capaz de controlar unos miedos (aquellos para los que se ha preparado) y otros no. La determinación de si un acto o una persona es o no virtuosa requiere, entonces, una comprensión suficientemente amplia del conjunto de la situación en que una determinada persona actúa. Este análisis debe tomar en cuenta muchas cosas: el conjunto de las circunstancias (qué, quién, cómo, cuándo, dónde, por qué, para qué, con qué medios), así como las motivaciones que desencadenan la acción o las posibles consecuencias de esta. Sólo una comprensión suficientemente amplia de nuestros actos nos permite hacer juicios sobre la virtud. Es por ello de suma importancia que los niños puedan examinar cada uno de los factores que determinan nuestra acción (circunstancias, motivos, consecuencias, reglas, modos de argumentación, etc.). En la medida en que adquieran esta capacidad de análisis podrán hacer mejores juicios morales. Hay aquí, sin embargo, un punto que no podemos dejar pasar por alto: hay juicios sobre la valentía referidos al acto o a la persona. De hecho, el adjetivo valiente se lo aplicamos indistintamente a los actos que realiza una persona o a la persona que realiza un acto. Decimos que son actos valientes, por ejemplo, rescatar a un herido; o decimos que es valiente el socorrista que rescata a un herido aun arriesgando su propia vida. Sin embargo, ¿son necesariamente valientes las personas que realizan actos valientes?, ¿o son necesariamente valientes los actos hechos por personas que son valientes? ¿Se podría dar el caso de que una persona que no es valiente haga un acto valiente? ¿O se podría dar el caso de una persona que es valiente haga un acto que no sea valiente? Seguramente sí. Si las virtudes son hábitos, es probable que alguien que no actúa habitualmente de forma valiente haga, accidentalmente, un acto valiente. También es posible que una persona que es habitualmente valiente realice un acto que no sea valiente (esa podría ser, tal vez, una forma de interpretar el caso del soldado que se asusta con un ratoncito). Las preguntas anteriores nos muestran lo importante que es analizar cada situación para comprender mejor hasta dónde ciertos actos o personas pueden ser o no calificados de valientes. El análisis de este tipo de situaciones es una de las mejores formas de cultivar la capacidad de razonamiento y de juicio moral de los niños. Los comentarios anteriores pretenden solamente mostrar algunas de las posibles líneas de indagación que nos abre este cuento. Desde luego, los propios niños -y también los maestrospueden encontrar allí muchos otros conceptos y problemas que pueden suscitar su interés y ayudarles a desarrollar una reflexión ética propia.

\section{Una observación final}

La educación moral no puede concebirse como una isla. Al contrario, está radicalmente entretejida con todas las áreas del currículo y con todo el proceso de formación de nuestros alumnos. Supone personas dispuestas a razonar de forma consistente, consecuente y coherente, y, por ello, recibe un aporte esencial de todas aquellas áreas, como las matemáticas, en donde se promueven formas de razonamiento ordenado y riguroso. Supone también un conocimiento del mundo y sus problemas, y, por ello, el conocimiento de la problemática local, nacional y mundial es un aporte fundamental a la formación del buen juicio moral de nuestros estudiantes. Supone una fina sensibilidad y un sentido de la proporción que cultivan, entre otras, las materias artísticas. Supone el fortalecimiento del carácter que se promueve 
también a través de la gimnasia y los deportes, y hasta un sentido de la sana competencia que forja un cuerpo sano y un carácter responsable. Supone un adecuado cultivo y examen de nuestras emociones, que modelan nuestras percepciones y juicios morales. Y supone, sobre todo, que nosotros, los maestros, y nuestros estudiantes, comprendamos que tiene sentido y que vale la pena luchar por nuestra felicidad personal y por la convivencia civilizada entre todos a pesar de las dificultades que vivimos día tras día.

Lo que se ofrece en textos como el que hasta aquí hemos comentado es sólo una forma, entre las muchas posibles, de promover en los niños su capacidad de reflexión ética. Los padres y maestros contamos, de todas maneras, con muchas formas diversas de promover este tipo de reflexión a través de las múltiples interacciones que con ellos tenemos en el hogar y en la escuela, y hasta los propios niños, en sus diálogos informales con sus amigos y amigas, podrían descubrir que reflexionar sobre el sentido de sus acciones puede ser, además de divertido, algo que hace que su vida resulte cada vez más significativa. Tal vez los propios niños puedan llegar a comprender el profundo sentido que se esconde tras esa hermosa frase de quien fue el propio creador de la reflexión ética, Sócrates, el gran filósofo ateniense: "Una vida sin examen no merece ser vivida".

\section{Bibliografía}

ARISTÓTELES. Ética nicomaquea. México: UNAM (Trad. de Antonio Gómez Robledo). 1968. BENNETT, William. El libro de las virtudes. Buenos Aires: Javier Vergara Editor. 1995.

DEWEY, John. "Teaching Ethics in the High School", in The Early Works of John Dewey, ed. By Jo Ann Boydston, Carbondale and Edwardsville, Southern Illinois University Press, London and Amsterdam, Feffer \& Simons Inc., Vol. 4, 1975, pp. 54-61.

Hegel, G. W. F. "La relación de la escuela y la enseñanza escolar con la formación ética del hombre", en Escritos pedagógicos. México: F. C. E., 2000, pp. 101-115.

LIPMAN, Matthew; Sharp, Ann Margaret and Oscanyan, Frederick: Philosophy in the Classroom. Philadelphia: Temple University Press. 1980.

LIPMAN, Matthew. Philosophy Goes to School. Philadelphia: Temple University Press. 1988. GARCÍA MORIYón, Félix (editor). Crecimiento moral y filosofía para niños. Bilbao: Desclée De Brouwer. 1988.

PINEDA RIVERA, Diego A. "La educación moral en 'Filosofía para niños", en García Moriyón, Félix (coord.): Matthew Lipman: Filosofía y educación. Madrid: Ediciones de la Torre. 2002, pp. 117-143.

"La educación moral desde la perspectiva de "Filosofía para niños", en Pineda, Diego y Kohan, Walter (comps.): Pensamiento, acción y sensibilidad: la mirada de “Filosofía para niños”. Bogotá: Beta. 2004, pp. 183-215.

. El miedo es para los valientes y otros cuentos para la reflexión ética, Bogotá, Beta. 2006.

PINEDA RiverA, Diego y Kohan, Walter O. "Filosofía e infancia". En: Hoyos Vásquez, Guillermo (edit.): Filosofía de la educación. Madrid: Trotta. 2008, pp. 293-320.

RYLE, Gilbert. “¿Puede enseñarse la virtud?”. En: Dearden, R. F., Hirst, P. H. y Peters, R. S.: Educación y desarrollo de la razón. Formación del sentido crítico. Madrid: Narcea. 1982, pp. 412-414. 
ZingAnO, Marco. "Paideia, virtud intelectual y virtud moral en la antigüedad". En: Hoyos Vásquez, Guillermo (edit.): Filosofía de la educación. Madrid: Trotta. 2008, pp. 55-75. 